\title{
EFEKTIVITAS METODE KOLABORATIF DAN KOOPERATIF DALAM PENDIDIKAN KESEHATAN BERBASIS KOMUNITAS
}

\author{
Tita Hariyanti*, Harsono**, Yayi S. Prabandari** \\ * Fakultas Kedokteran Universitas Brawijaya, Malang \\ ** Fakultas Kedokteran Universitas Gadjah Mada, Yogyakarta
}

\begin{abstract}
Background: The role of the learning methods is changing from teacher centered learning to student centered learning (SCL). One of the SCL methods is collaborative and cooperative learning. The past twenty years have seen an increase in collaborative and cooperative learning based pedagogies in colleges, but not in community based health education. Aim: To identify the efectivity of collaborative and cooperative learning in community based health education Method: This research used quasi experimental non-randomized control group post test design. Respondent of the research are 111 geriatric cadres of Kecamatan Kepanjen and 72 geriatric cadres of Kecamatan Singosari.

Results and Discussion: Data shows that cadre's knowledge in first training, 30 and 90 days after first training increased in both groups $(p<0,001)$. There is no relationship between individual characteristic (age, education, occupation, time to work as a cadre, training) and increase of knowledge $(p>0,05)$

Conclusions: Collaborative and cooperative method can increase cadre's knowledge of stroke effectively and maintain memory retention longer than conventional method.
\end{abstract}

Keywords: stroke, increase of knowledge, memory retention, collaborative and cooperative learning, cadre.

\section{ABSTRAK}

Latar Belakang: Saat ini, proses pembelajaran lebih ditekankan pada proses belajar aktif dan mandiri (student centered learning). Salah satu metode pembelajaran model ini adalah dengan metode kolaboratif dan kooperatif (collaborative and cooperative learning). Metode kolaboratif dan kooperatif lazim digunakan pada pendidikan formal, namun masih jarang digunakan untuk pelatihan atau pendidikan kesehatan berbasis komunitas.

Tujuan: Penulisan ini bertujuan untuk mengetahui efektivitas metode kolaboratif dan kooperatif pada pelatihan kader lansia tentang stroke di Kabupaten Malang.

Metode: Penulisan ini menggunakan quasi experimental non-randomized control group pretest-postest design. Responden penulisan adalah 111 orang kader lansia di Kecamatan Kepanjen dan 72 orang dari Kecamatan Singosari. Hasil dan Pembahasan: Data menunjukkan terjadi peningkatan pengetahuan antara kedua kelompok kader mulai dari pelatihan pertama, 30 dan 90 hari setelah pelatihan $(p<0,001)$. Karakter kader yang meliputi usia, tingkat pendidikan, pekerjaan, lama menjadi kader, dan pelatihan yang pernah diikuti, tidak berhubungan dengan peningkatan pengetahuan $(\mathrm{p}>0,5)$.

Kesimpulan: Metode kolaboratif dan kooperatif efektif dalam meningkatkan pengetahuan, dan mempertahankan ingatan tentang pengetahuan tersebut lebih lama dibandingkan dengan metode konvensional.

Kata Kunci: stroke, peningkatan pengetahuan, retensi memori, metode belajar kolaboratif dan kooperatif, kader.

Korespondensi: tita.hariyanti@gmail.com 


\section{PENDAHULUAN}

Dalam satu dekade terakhir, stroke menempati urutan pertama dari 10 penyakit degeneratif terbanyak di Indonesia. ${ }^{1}$ Selain angka mortalitas stroke menempati urutan tertinggi, angka kesakitan stroke juga menempati urutan ketiga di dunia, dan sebesar $55 \%$ penderita stroke mengalami kecacatan. ${ }^{2}$ Penyakit stroke dengan gejala yang sangat bervariasi, sering sulit dikenali oleh kalangan petugas kesehatan sekalipun. Banyak terjadi keterlambatan penanganan kasus stroke yang disebabkan oleh pengetahuan yang kurang dari penderita, keluarganya, maupun petugas kesehatan yang menangani. ${ }^{3}$

Di Indonesia, yang menjadi ujung tombak upaya pencegahan primer pelayanan kesehatan adalah puskesmas dan aparatnya. Dokter, perawat, bidan, kader, bahkan pamong desa, bersama-sama berusaha mewujudkan kesehatan masyarakat. Berdasarkan Keputusan Menteri Kesehatan RI nomor 1457/ MENKES/SK/X/2003 tentang Standar Pelayanan Minimal Bidang Kesehatan di Kabupaten/Kota disebutkan bahwa setiap kabupaten atau kota diwajibkan menyelenggarakan pelayanan kesehatan sesuai dengan standar pelayanan minimal. Standar pelayanan minimal (SPM) ini salah satunya adalah pelayanan kesehatan pralansia dan lansia. SPM ini dilakukan mulai dari pemerintah kabupaten/kota ke bawah. ${ }^{4}$ Intitusi pelayanan kesehatan yang berada di ujung tombak adalah pos pelayanan terpadu (posyandu). Sesuai dengan Peraturan Menteri Dalam Negeri Nomor 19 Tahun 2011, penyelenggara posyandu adalah anggota masyarakat yang disebut dengan kader posyandu. ${ }^{5}$ Kader posyandu ini sering bekerja sama dengan petugas kesehatan (bidan, perawat, dokter) untuk menyampaikan informasi tentang kesehatan atau program kesehatan dari puskesmas. Oleh karena itu, pemerintah memberikan berbagai pelatihan untuk meningkatkan pengetahuan kader.

Berdasarkan wawancara tidak terstruktur, pemerintah daerah telah memberikan berbagai pelatihan kepada kader, terutama tentang permasalahan ibu dan balita. Kader belum pernah sama sekali mengikuti pelatihan tentang stroke. Metode yang digunakan pelatihan selama ini adalah metode konvensional (one way traffic). Sementara saat ini, proses pembelajaran lebih ditekankan pada proses belajar aktif dan mandiri (student centered learning) dibandingkan dengan pembelajaran pasif atau konvensional (teacher centered learning). Sistem pembelajaran konvensional yang selama ini dilakukan kental dengan suasana instruksional dan kurang sesuai dengan dinamika perkembangan ilmu pengetahuan dan teknologi yang pesat. Selain itu, jika tujuan pembelajaran ingin memasukkan nilai moral, budi pekerti luhur, kreativitas, kemandirian, dan kepemimpinan, sangat sulit dilakukan pada metode pembelajaran konvensional. Alasan ini yang menyebabkan sistem pembelajaran bergeser ke arah student centered learning. Salah satu metode pembelajaran model ini adalah dengan metode pembelajaran kolaboratif dan kooperatif (collaborative and cooperative learning). Pembelajaran kolaboratif adalah proses belajar kelompok yang setiap anggotanya menyumbangkan informasi, pengalaman, ide, sikap, pendapat, kemampuan, dan keterampilan yang dimilikinya untuk secara bersama-sama saling meningkatkan pemahaman seluruh anggota. ${ }^{6}$ Metode kolaboratif dan kooperatif lazim digunakan pada pendidikan formal ${ }^{7}$ dan merupakan keniscayaan bagi perguruan tinggi. ${ }^{8}$ Namun metode ini masih jarang digunakan untuk pelatihan atau pendidikan kesehatan berbasis komunitas.

Penulisan ini bertujuan melihat efektivitas metode kolaboratif dan kooperatif dalam pendidikan kesehatan berbasis komunitas. Penulis akan melakukan pelatihan tentang stroke dengan membandingkan dua kelompok kader lansia di kecamatan yang berbeda. Kader lansia yang ada di Kecamatan Kepanjen akan dilatih tentang stroke dengan menggunakan metode kolaboratif dan kooperatif, sedangkan kader di Kecamatan Singosari akan dilatih dengan metode konvensional. Harapannya, kader yang dilatih dengan metode kolaboratif dan kooperatif ini dapat memahami gejala, faktor risiko, pencegahan, dan penanganan stroke lebih baik sehingga lebih mudah menyampaikan kepada masyarakat. Selain itu, peserta dirangsang untuk berpartisipasi aktif dalam diskusi agar terjadi proses transfer pengetahuan antar peserta sehingga menimbulkan retensi kuat tentang stroke. Metode ini juga merangsang kemandirian, kepemimpinan, kreativitas yang diperlukan saat menjalankan tugasnya. Kemampuan kader tersebut diperlukan untuk menjaga rantai keselamatan dan pemulihan stroke, karena sebagai pengelola posyandu kader dapat berperan aktif dalam memberikan pengetahuan tentang pengenalan tentang tanda dan gejala stroke (detection) serta mengaktivasi orang untuk segera memobilisasi pasien ke rumah sakit (dispatch). ${ }^{9}$ 


\section{METODE}

Rancangan penulisan yang digunakan pada penulisan ini adalah quasi experiment non-randomized control group pretest postest design. Kader dari dua kecamatan dikelompokkan menjadi dua kelompok yaitu kelompok eksperiman dan kelompok kontrol. Pada kelompok intervensi, kader diberi perlakuan dengan memberikan pelatihan metode kolaboratif dan kooperatif dan brosur serta poster sebagai alat penyuluhan sebagai kader lansia. Pelatihan juga diberikan pada kelompok kontrol, namun dengan metode konvensional. Pelatihan ini bertujuan meningkatkan pengetahuan kader tentang stroke sehingga dapat memberikan penyuluhan serta motivasi kepada masyarakat sehubungan dengan stroke. Kedua kecamatan terpilih oleh karena mempunyai karakteristik yang sama baik kota, masyarakat, maupun kadernya. Kedua kota kecamatan ini terletak di Kabupaten Malang, namun terpisah $40 \mathrm{~km}$ jauhnya. Singosari terletak 15 $\mathrm{km}$ di sebelah utara Kota Malang, sedangkan Kepanjen terletak $25 \mathrm{~km}$ sebelah selatan Kota Malang.

Pada kelompok intervensi (kader Kecamatan Kepanjen), jumlah kader yang terlibat adalah 100 orang. Peserta tersebut mewakili 99 posyandu lansia yang tersebar di 18 desa di Kecamatan Kepanjen. Setiap posyandu, mengirimkan satu wakilnya untuk mengikuti pelatihan. Jumlah total kader lansia di Kecamatan Kepanjen pada akhir tahun 2012 adalah 545 kader. Seluruh peserta pelatihan ini terbagi rata ke dalam 3 gelombang. Pada saat pelatihan, setiap gelombang membutuhkan waktu
2 hari, hari pertama dan kedua berjarak 3 hari. Misalnya gelombang pertama, hari pertama dilaksanakan pada hari Senin, dan hari kedua pelatihan dilaksanakan pada hari Kamis. Peserta terbagi dalam 5 kelompok. Setiap kelompok terdiri dari 6 - 7 orang kader yang berasal dari desa yang berbeda, didampingi oleh satu orang fasilitator. Heterogenitas kelompok sengaja dibuat dengan tujuan agar terjadi pertukaran pengetahuan (transfer of knowledge) antar peserta. ${ }^{7,8}$

Di hari pertama pada kelompok intervensi, peserta diminta mengerjakan pre test sebelum memulai pelatihan. Pada saat memulai proses pelatihan, setiap kelompok diminta untuk memilih ketua dan sekretaris. Kemudian peserta diminta untuk membaca masingmasing skenario selama 10 menit. Setelah membaca skenario ini, peserta diminta menuliskan jawaban masing-masing dari semua pertanyaan pada kertas yang telah disediakan. Setelah selesai, ketua kelompok memimpin jalannya diskusi di setiap kelompok sampai dihasilkan keputusan kelompok. Terakhir, masing-masing kelompok diminta untuk membagikan hasil diskusi mereka kepada kelompok lain. Di akhir hari pertama, peserta diberi buku saku kader yang berisi materi tentang stroke, posyandu lansia, serta lansia dan permasalahannya. Hari kedua pelatihan diadakan 3 hari berikutnya. Setiap kelompok diminta mengulang proses yang sama dengan hari pertama, namun dengan pengetahuan (prior knowledge) yang berbeda. Di akhir sesi hari kedua, peserta diminta mengerjakan post test.

\section{Salah satu skenario tentang stroke dengan judul: S A N T E T}

Di suatu pagi menjelang subuh, Marwati mengagetkan suaminya yang masih tidur di sebelahnya dengan erangannya. Suaminya kaget dan terbangun.

"Ti, kowe kenopo Tiii..?"

"Uhhhh.... Uhhhh..."

Marwati tidak bisa bicara, dia hanya mengerang dan menangis. Marwati mendapati dirinya tidak bisa bergerak. Suaminya tergopoh-gopoh melihat keadaan Marwati, karena semalam ketika tidur Marwati masih baik-baik saja. Semua orang di rumah itu dibangunkan karena suaminya tidak tahu harus berbuat apa. Akhirnya tetangganya berdatangan mendengar ada keributan di rumah Marwati pada saat subuh. Para tetangga itu mencoba membantu Marwati yang mendadak tidak bisa bicara dan bergerak itu. Ada yang menyuruh merebus air sampai panas untuk mengompres tangan dan kakinya biar lemas, ada yang menyuruh memanggil tukang pijet, ada yang menyuruh banyak membaca istighfar, ada yang menawari kerokan untuk meringankan sakitnya.

Dari sekian banyak saran, ada satu saran dari sesepuh yang dipertimbangkan oleh suami Marwati, yaitu saran Pak Karno, sesepuh di kampung itu. Pak Karno menyarankan agar Marwati dibawa ke paranormal. Beliau curiga sakit Marwati karena disantet orang karena terjadinya mendadak, dan santet biasanya datang pada malam hari. Maklum, Marwati adalah penyanyi dangdut terkenal dan laris di kampung itu. Walaupun berusia 43 tahun, Marwati 
cantik, singset, dan mempunyai suara merdu, sehingga membuat dia sering dipanggil jika orang mempunyai hajat. Banyak orang yang tidak suka pada ketenaran Marwati tersebut.

Sambil menunggu pagi, Marwati dikeroki dan dipijat oleh tetangganya. Setelah hari agak siang, Marwati dibawa ke rumah paranormal. Oleh sang paranormal diberi jampi-jampi sebagai penolak bala. Setelah seminggu di rumah dan meminum ramuan berisi jampi-jampi dari paranormal tersebut, Marwati merasa tidak ada perbaikan pada kesehatannya. Dia masih tetap pelat dan tangan serta kakinya tidak bisa digerakkan separuh. Setelah satu bulan dibawa ke paranormal lagi dan keadaan Marwati tidak berubah, suami Marwati memutuskan untuk membawa Marwati ke dokter.

Bahan diskusi:

1. Apa yang dialami Marwati?

2. Apa alasan Anda?

3. Apa penyebab Marwati mengalami hal tersebut?

4. Apakah tindakan Marwati membawa ke paranormal tersebut tepat? Jika ya jelaskan alasannya! Jika tidak, bagaimana seharusnya?

Pada kelompok kontrol (kader Kecamatan Singosari), jumlah kader yang terlibat adalah 72 orang. Kader ini berasal dari 35 posyandu lansia yang tersebar di 9 desa. Kader diberi materi tentang stroke dengan metode konvensional atau klasikal. Di sesi akhir, peserta diminta mengerjakan post test.

Setelah pelatihan pertama, kedua kelompok kader diminta berkumpul kembali 90 dan 120 hari setelahnya. Kegiatan utama ketika berkumpul adalah mengerjakan post test tentang stroke, dan diberikan materi tentang diabetes melitus dan hipertensi sebagai faktor risiko stroke. Materi diabetes melitus dan hipertensi ini diberikan dengan menggunakan metode konvensional. Pelatihan ini juga diselingi dengan kegiatan lomba dan beberapa permainan untuk memecah suasana (ice breaking).

\section{HASIL DAN PEMBAHASAN}

Tabel 1 menunjukkan beberapa perbedaan karakteristik kader di kedua kelompok. Terdapat perbedaan signifikan ( $<<0,01$ ) pada usia di kedua kelompok. Para kader di kelompok intervensi rata-rata berusia lebih muda $(43,3$ tahun) dibandingkan kelompok kontrol (53,9 tahun). Karakter lain yang meliputi lama menjadi kader, tingkat pendidikan, status pekerjaan, dan pengalaman mengikuti pelatihan, tidak ada perbedaan yang signifikan pada kedua kelompok kader. Jumlah kader di kedua kelompok merupakan jumlah keseluruhan kader yang mengikuti

Tabel 1. Karakteristik kader kedua kelompok

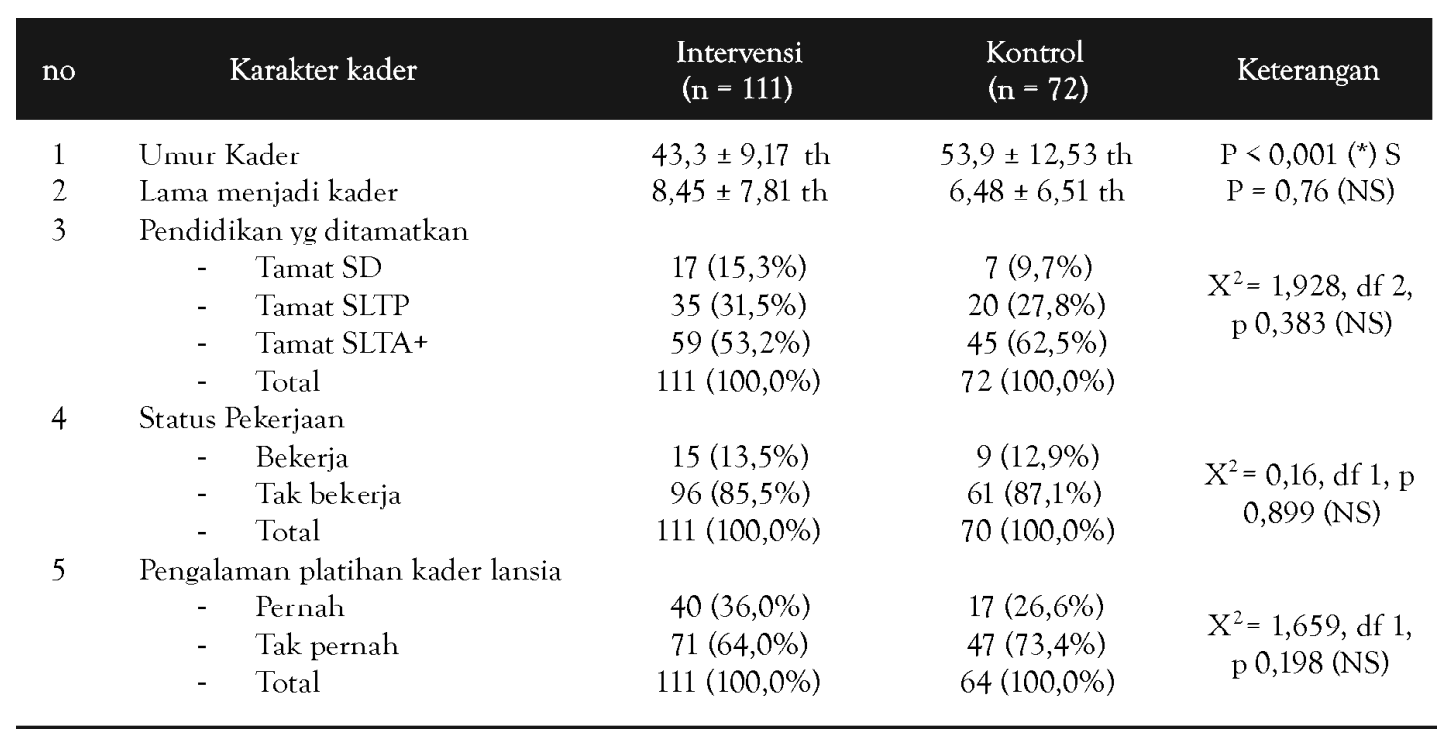


pelatihan dari awal hingga akhir. Terdapat beberapa orang kader yang mengikuti sebuah pelatihan, dan tidak mengikuti pelatihan yang lain. Perbedaan umur kader dan lama menjadi kader antar kedua kelompok diuji dengan independent t-test, sedang perbedaan tingkat pendidikan, status pekerjaan dan pengalaman mengikuti pelatihan, diuji dengan uji-chi kwadrat.

Tabel 2 menunjukkan gambaran pengetahuan dari kedua kelompok. Post test yang diberikan ini terdiri dari dua kelompok pertanyaan, yaitu tentang stroke dan posyandu lansia. Terdapat perbedaan pengetahuan yang signifikan di kedua kelompok ( $<<0,001)$. Mulai dari pelatihan pertama hingga terakhir, tampak ada penurunan jumlah kader yang mengikuti pelatihan. Namun ternyata, terdapat peningkatan skor yang menggembirakan di kedua kelompok, dengan tingkat pengetahuan dan penguasaan materi tentang stroke dan posyandu lansia lebih baik pada kelompok intervensi dibandingkan kelompok kontrol. Perbedaan tingkat pengetahuan ini diuji dengan menggunakan independent t-test.

Potensi kader dalam menyuluh masyarakatnya dengan benar ditentukan oleh jumlah atau prosentase kader yang memiliki pengetahuan stroke yang benar 100\%. Karena itu Tabel 3 ini dibuat untuk mengetahui seberapa banyak jumlah kader yang potensial menjadi penyuluh yang baik dan benar dalam mensosialisasikan pengetahuan stroke. Terlihat bahwa kader kelompok intervensi memiliki tren retensi pengetahuan lebih tinggi dibanding kader kelompok kontrol. Sampai hari ke 120 (4 bulan pasca pelatihan), jumlah kader potensial (yang masih memiliki pengetahuan stroke $100 \%$ benar) masih diatas $85 \%$ di kelompok intervensi, dibanding 50\% di kelompok kontrol. Tren persentase jumlah kader yang masih memiliki pengetahuan stroke dengan benar, terutama di kelompok intervensi, terlihat semakin meningkat dan relatif stabil setelah pengukuran hari ke-90. Dari 68,4\% di pelatihan pertama, menjadi $86,4 \%$ dan $85 \%$ pada hari ke- 90 dan hari ke-120. Sementara itu di kelompok kontrol, kenaikan persentase kader yang memiliki pengetahuan benar tentang stroke lebih rendah dari $25 \%$ di pelatihan pertama, meningkat pada hari ke-90 menjadi 60,6\% dan kemudian menurun menjadi $50 \%$ pada hari ke- 120 .

Tabel 2. Beda pengetahuan kader di kedua kelompok pada post test pelatihan hari pertama, hari ke-90, dan hari ke-120

\begin{tabular}{|c|c|c|c|c|}
\hline No & Periode asesmen & $\begin{array}{l}\text { Intervensi } \\
\quad(\mathbf{n}=99)\end{array}$ & $\begin{array}{l}\text { Kontrol } \\
(n=48)\end{array}$ & Keterangan \\
\hline 1 & $\begin{array}{l}\text { Pengukuran pelatihan pertama } \\
\text { - Pengetahuan tentang stroke } \\
\text { - Pengetahuan tentang posyandu lansia } \\
\text { Skor total }\end{array}$ & $\begin{array}{l}19,9+1,69 \\
11,2+1,56 \\
31,1+2,48\end{array}$ & $\begin{array}{c}17,7+2,18 \\
8,8+1,31 \\
26,5+2,81\end{array}$ & $\begin{array}{l}t=6,6 ; p<0.01 \\
t=6,9 ; p<0,01 \\
t=9,9 ; p<0,01\end{array}$ \\
\hline 2 & $\begin{array}{l}\text { Pengukuran } 90 \text { hari pasca pelatihan pertama } \\
\text { - Pengetahuan tentang stroke } \\
\text { - Pengetahuan tentang posyandu lansia } \\
\text { Skor total }\end{array}$ & $\begin{array}{c}(\mathrm{n}=88) \\
20,7+1,65 \\
11,8+1,65 \\
32,5+2,64\end{array}$ & $\begin{array}{c}(\mathrm{n}=33) \\
19,2+2,21 \\
9,3+2,09 \\
28,6+3,67\end{array}$ & $\begin{array}{l}t=4,0 ; t<1,01 \\
t=4,7 ; t<0,01 \\
t=6,6 ; t<0.01\end{array}$ \\
\hline 3 & $\begin{array}{l}\text { Pengukuran } 120 \text { hari pelatihan pertama } \\
\text { - Pengetahudı tenllang stroke } \\
\text { - Pengetahuan tentang posyandu lansia } \\
\text { Skor total }\end{array}$ & $\begin{array}{c}(\mathrm{n}=83) \\
20,8+1,38 \\
11,6+1,63 \\
32,1+3,34\end{array}$ & $\begin{array}{c}(\mathrm{n}=34) \\
19,0+2,05 \\
10,3+1,88 \\
29,3+2,71\end{array}$ & $\begin{array}{l}\mathrm{t}=5,3 ; \mathrm{p}<0,01 \\
\mathrm{t}=3,7 ; \mathrm{p}<0,01 \\
\mathrm{t}=4,3 ; \mathrm{p}<0,01\end{array}$ \\
\hline
\end{tabular}


Tabel 3 Persentase kader yang memiliki skor nilai benar maksimal pada pelatihan pertama, hari ke-90 dan ke 120 pasca pelatihan

\begin{tabular}{|c|c|c|c|c|c|}
\hline \multirow{3}{*}{ no } & \multicolumn{5}{|c|}{ \% kader yg memiliki pengetahuan stroke } \\
\hline & \multirow[t]{2}{*}{ Periode asesmen } & \multicolumn{3}{|c|}{$100 \%$ benar } & \multirow[b]{2}{*}{ Keterangan } \\
\hline & & Kel. intervensi & Kel. kontrol & Total & \\
\hline \multirow[t]{3}{*}{1} & Pelatihan pertama & & & & \\
\hline & Pengetahuan stroke & $67(68,4 \%)$ & $12(25,0 \%)$ & $79(54,1 \%)$ & $\mathrm{X}^{2}=24,4 ; \mathrm{p}<0,001$ \\
\hline & Pengetahuan Yandu Lansia & $44(44,4 \%)$ & $2(4,3 \%)$ & $46(31,5 \%)$ & $X^{2}=23,8 ; p<0,001$ \\
\hline \multirow[t]{3}{*}{2} & Hari ke-90 pasca pelatihan & & & & \\
\hline & Pengetahuan stroke & $76(86,4 \%)$ & $20(60,6 \%)$ & $96(79,3 \%)$ & $X^{2}=9,7 ; p=0,002$ \\
\hline & Pengetahuan yandu lansia & $53(60,2 \%)$ & $8(24,2 \%)$ & $61(50,4 \%)$ & $X^{2}=12,4 ; p<0,001$ \\
\hline \multirow[t]{3}{*}{3} & Hari ke-120 pasca pelatihan & & & & \\
\hline & Pengetahuan stroke & $70(85,4 \%)$ & $17(50 \%)$ & $87(75,0 \%)$ & $X^{2}=16,03 ; p<0,001$ \\
\hline & Pengetahuan yandu lansia & $51(63,0 \%)$ & $10(29,4 \%)$ & $61(53,0 \%)$ & $X^{2}=10,8 ; p=0,001$ \\
\hline
\end{tabular}

Tabel 4 menunjukkan hasil hubungan antara karakter kader dengan skor pengetahuan tentang stroke di kedua kelompok. Pada tabel ini, Umur kader dikategorikan' dibawah' dan 'diatas' umur rata-rata kader (43 tahun); Tingkat pendidikan dikategorikan menjadi 3 ('tamatan SD', 'tamatan SLTP', dan 'tamatan SLTA ke atas'); Status Bekerja dikategorikan 'bekerja' dan 'tidak bekerja; Lama menjadi kader dikategorikan 'dibawah' dan 'diatas' nilai rata-rata lama menjadi kader (5 tahun); Pernah mengikuti pelatihan kader yandu lansia dikategorikan 'pernah' dan 'tidak pernah'. Dari tabel 4 ini, dapat disimpulkan bahwa latar belakang karakteristik kader di kedua kelompok tidak berasosiasi dengan peningkatan pengetahuan kader tentang stroke, baik pada pengukuran pelatihan pertama, 90 hari pasca pelatihan, dan 120 hari pasca pelatihan.

Tabel 4. Asosiasi antara karakter kader dengan skor pengetahuan tentang stroke di kedua kelompok

\begin{tabular}{|c|c|c|c|c|c|c|c|}
\hline \multirow[t]{2}{*}{ No } & \multirow{2}{*}{$\begin{array}{l}\text { Karakteristik } \\
\text { Kader }\end{array}$} & \multicolumn{3}{|c|}{$\begin{array}{l}\text { Asosiasi dengan skor pengetahuan stroke } \\
\text { kelompok intervensi }\end{array}$} & \multicolumn{3}{|c|}{$\begin{array}{c}\text { Asosiasi dengang skor pengetahuan } \\
\text { stroke kelompok kontrol }\end{array}$} \\
\hline & & Pelatihan 1 & Hari ke90 & Hari ke-120 & Pelatihan 1 & Hari ke-90 & Hari ke-120 \\
\hline \multirow[t]{2}{*}{1} & Umur Kader & $\mathrm{MW}=1081$ & $\mathrm{MW}=968$ & $\mathrm{MW}=713$ & $\mathrm{MW}=136,5$ & $\mathrm{MW}=93$ & $M W=102$ \\
\hline & & $\mathrm{P}=0, .312$ & $\mathrm{p}=1.000$ & $\mathrm{p}=0,216$ & $\mathrm{p}=0,096$ & $\mathrm{p}=0,763$ & $\mathrm{p}=0,934$ \\
\hline \multirow[t]{2}{*}{2} & Tkt Pendidikan & $X 2=7,827$ & $X 2=1,652$ & $X 2=1,216$ & $X 2=2,269$ & $X 2=5,719$ & $X 2=3,804$ \\
\hline & & $\mathrm{p}=0,020$ & $\mathrm{p}=0,438$ & $\mathrm{p}=0,544$ & $\mathrm{p}=0,322$ & $\mathrm{p}=0,057$ & $\mathrm{p}=0,149$ \\
\hline \multirow[t]{2}{*}{3} & Status Bekerja & $\mathrm{MW}=572,5$ & $\mathrm{MW}=277,5$ & $\mathrm{MW}=357$ & $\mathrm{MW}=75,5$ & $\mathrm{MW}=27,5$ & $\mathrm{MW}=55,0$ \\
\hline & & $\mathrm{p}=0,817$ & $p=0,053$ & $\mathrm{p}=0,388$ & $p=0,456$ & $\mathrm{p}=0,842$ & $\mathrm{p}=0,509$ \\
\hline \multirow[t]{2}{*}{4} & Lama menjadi & $\mathrm{MW}=1075$ & $\mathrm{MW}=775$ & $\mathrm{MW}=820,5$ & $\mathrm{MW}=132,0$ & $\mathrm{MW}=87,0$ & $\mathrm{MW}=70,0$ \\
\hline & kader & $\mathrm{p}=0,283$ & $\mathrm{p}=0,091$ & $\mathrm{p}=0,850$ & $\mathrm{p}=0,116$ & $\mathrm{p}=0,218$ & $\mathrm{p}=0,299$ \\
\hline \multirow[t]{2}{*}{5} & Pernah pelatihan & $\mathrm{MW}=1101$ & $\mathrm{MW}=721$ & $\mathrm{MW}=786,5$ & $\mathrm{MW}=168,0$ & $\mathrm{MW}=82,0$ & $\mathrm{MW}=65,5$ \\
\hline & & $p-0,670$ & $p-0,055$ & $p-0,772$ & $p^{-0,503}$ & $p-0,319$ & $p^{-0,800}$ \\
\hline
\end{tabular}

Hubungan antara Karakteristik Kader dengan Peningkatan Pengetahuan

Pada penulisan ini, ternyata tidak ada perbedaan karakter antara kader Kecamatan Kepanjen sebagai sebagai kelompok intervensi dengan kader Kecamatan Singosari sebagai kelompok kontrol. Usia kader di Kecamatan Kepanjen relatif lebih muda dibandingkan kader Singosari. Pada wawancara tidak terstruktur, penulis 
menjumpai sebuah kesepakatan di Singosari bahwa untuk menjadi kader posyandu lansia, sebaiknya orang yang berusia lansia agar dapat memahami karakter para lansia. Padahal syarat menjadi kader adalah (1) diutamakan penduduk daerah setempat, (2) bisa membaca dan menulis, (3) mempunyai jiwa pelopor, (4) bersedia bekerja secara sukarela, memiliki kemampuan dan waktu luang ${ }^{5}$. Sebagian besar kader berpendidikan tamatan SMA dan lebih tinggi, serta tidak bekerja. Kedua karakter ini sangat mendukung profesi sebagai kader, karena kader kesehatan atau yang lebih umum disebut sebagai kader posyandu merupakan pembawa misi pembangunan kesehatan ditingkat paling bawah. Kader ini adalah kepanjangan tangan dari puskesmas atau Dinas Kesehatan kepada masyarakat di wilayah kerjanya. Tenaga sukarelawan ini berasal dari masyarakat yang peduli terhadap kesehatan warga sekitarnya. Sampai saat ini kader kesehatan terkadang menjadi sumber rujukan bagi penanganan berbagai masalah kesehatan ${ }^{10}$.

Meskipun merancang sebuah metode yang akan digunakan dalam pelatihan itu dipengaruhi oleh karakteristik dan latar belakang pengetahuan yang dimiliki peserta ${ }^{11}$, namun dalam penulisan ini tidak dijumpai hubungan antara karakteristik kader dengan peningkatan pengetahuan tentang stroke. Kader dengan berbagai latar belakang usia, tingkat pendidikan, pekerjaan, lama menjadi kader, kepesertaan mengikuti pelatihan, tidak berhubungan dengan peningkatan pengetahuan tentang stroke dan pelayanan posyandu.

\section{Hubungan antara Metode Kolaboratif dan Kooperatif dengan Peningkatan Pengetahuan}

Beberapa pertanyaan diajukan kepada kader tentang metode yang digunakan untuk pelatihan yang telah diberikan selama ini. Sebagian besar menyatakan bahwa metode yang digunakan untuk pelatihan adalah ceramah dan tanya jawab, serta praktek. ${ }^{10,12}$ Penulisan ini bertujuan melihat efektivitas metode kolaboratif dan kooperatif pada kader. Metode tersebut umum digunakan pada pendidikan tinggi. ${ }^{13}$ Metode kolaboratif dan kooperatif merupakan pembelajaran yang dilakukan oleh peserta didik dengan berbagai maca latar belakang secara bersama-sama. Peserta diharapkan menggunakan pengetahuan yang telah dimilikinya (prior knowledge) untuk melaksanakan metode ini secara aktif dan interaktif, dan tidak seorang peserta pun yang diam atau dalam keadaan pasif. Di dalam kelompok diskusi, tiaptiap individu berperan aktif, saling memberi kontribusi, saling menerima pendapat kawan dengan prasangka baik, saling menghargai kemampuan orang lain. Pembelajaran kolaboratif ini lebih menekankan saling bagi pengalaman dan pendapat, dan bukan merupakan kompetisi di antara pembelajar. ${ }^{7,14,15}$

Hari pertama pelatihan pada kelompok intervensi, kader diminta untuk mendiskusikan 3 skenario. Skenario yang digunakan berbeda di setiap gelombang, namun mempunyai tujuan yang sama. Skenario pertama bertujuan untuk memperkenalkan metode kolaboratif dan kooperatif, skenario kedua bertujuan untuk menggali pengetahuan tentang stroke, dan yang ketiga bertujuan untuk menggali pengetahuan tentang peran dan fungsi kader lansia. Proses diskusi ini dibiarkan mengalir tanpa intervensi dari fasilitator dan tanpa ada penjelasan dulu tentang skenario tersebut. Masing-masing peserta hanya diminta untuk membaca skenario, menjawabnya sendiri terlebih dahulu, dan kemudian berdiskusi sesuai dengan pengetahuan yang dimiliki. Setiap kelompok menuliskan hasil diskusi di kertas lembar balik (flip chart). Hasil diskusi kelompok ini kemudian dipaparkan dan didiskusikan antar kelompok. Setiap kelompok diminta untuk mewakilkan orang yang berbeda dalam memaparkan hasil pada setiap skenario, sesuai dengan langkah-langkah dalam metode kolaboratif dan kooperatif. ${ }^{7,14,15}$ Di akhir sesi pelatihan hari pertama, penulis membagikan buku saku untuk kader lansia. Pada buku tersebut terdapat penjelasan tentang lanjut usia dan permasalahannya, kader dan posyandu, serta stroke. Seluruh peserta diminta membaca buku tersebut.

Hari kedua pelatihan, yaitu 3 hari setelah pelatihan hari pertama, seluruh peserta diminta mendiskusikan skenario yang sama dengan hari pertama. Bedanya, pada hari kedua peserta memiliki latar belakang pengetahuan karena diharapkan telah membaca buku saku yang dibagikan. Diskusi yang terjadi pada hari ini membutuhkan waktu lebih singkat daripada sebelumnya. Setelah melakukan diskusi antar kelompok, penulis memberikan materi tentang stroke untuk menyamakan persepsi. Materi yang diberikan meliputi gejala, faktor risiko, pencegahan, dan penanganan awal stroke, lansia 
dan permasalahannya, serta peran kader pada posyandu lansia. Metode ini merangsang partisipasi aktif dari setiap peserta, sesuai dengan tujuannya. Terdapat 5 pilar dalam metode kooperatif, yaitu (1) Anggota kelompok harus berbagi pengetahuan dalam saling ketergantungan secara positif (positive interdependence), (2) Setiap anggota kelompok harus saling kerjasama (promotive, face to face interaction), (3) Anggota kelompok harus mempunyai rasa tanggung jawab dan tanggung gugat (individual accountability), (4) Anggota kelompok harus trampil dalam kerjasama kelompok (social skills), (5) Kelompok harus mengevaluasi proses diskusinya (group processing) ${ }^{7}$. Kelima pilar ini dapat dilalui oleh kader yang berada dalam kelompok intervensi.

Dari hasil penulisan, didapatkan peningkatan pengetahuan setelah pelatihan baik dengan metode kolaboratif dan kooperatif maupun pelatihan metode konvensional. Namun, kader Kepanjen yang dilatih menggunakan pendekatan kolaboratif dan kooperatif memiliki tren retensi pengetahuan lebih tinggi dibanding kader Singosari, bahkan setelah 120 hari setelah pelatihan pertama. Melihat bahwa karakteristik tidak berpengaruh terhadap peningkatan pengetahuan, maka besar dugaan penulis bahwa perbedaan peningkatan pengetahuan kader tentang stroke di kedua kelompok kemungkinan dipengaruhi oleh metode pendekatan pelatihan kader. Kader Kepanjen yang dilatih menggunakan metode kolaboratif dan kooperatif tampaknya dapat membuat para kader aktif belajar pengetahuan tentang stroke. Hal ini yang menyebabkan peningkatan pengetahuan dan retensi memori tentang stroke bertahan lebih lama dibandingkan dengan kader yang dilatih dengan metode konvensional?

Proses pelatihan konvensional yang diterapkan di Singosari pun tidak dapat berjalan sesuai rencana. Seharusnya, kader diberikan pre dan post test pada saat pelatihan pertama. Namun sampai dengan acara pelatihan dimulai, kader yang datang baru setengah dari undangan, sehingga beberapa kader mengisi pre test saat penulis memberikan materi. Kejadian ini menjadikan keterbatasan penulisan, karena pre test di kelompok kontrol tidak dapat dilaksanakan sehingga tidak dapat dibandingkan dengan kelopok intervensi. Kader Singosari yang berada di kelompok kontrol tampak mengalami penurunan skor pengetahuan beberapa poin pada hari ke-120 setelah pelatihan. Gambaran ini menunjukkan bahwa retensi memori pada kader Singosari yang dilatih dengan metode konvensional dan cenderung pasif saat pelatihan, tidak terlalu bagus. Penulis menyarankan perlunya upaya mempertahankan tingkat pengetahuan kader secara berkala agar para kader mampu mendiseminasikan permasalahan kesehatan dengan handal.

\section{KESIMPULAN}

Metode kolaboratif dan kooperatif ternyata tidak hanya efektif digunakan dalam pendidikan tinggi, namun juga untuk pendidikan kesehatan berbasis komunitas. Metode ini juga dapat meningkatkan pengetahuan kader tentang stroke, serta mempertahankan memori tersebut lebih lama dibandingkan dengan metode konvensional. Karakteristik kader, seperti usia, jenis kelamin, pendidikan, pekerjaan, dan jenis pelatihan yang pernah diikuti, tidak berhubungan terhadap efektivitas metode kolaboratif dan kooperatif.

\section{DAFTAR PUSTAKA}

1. Departemen Kesehatan RI. Profil Kesehatan Indonesia 2008. Jakarta, 2009.

2. Adams H, Adams R, Zoppo GD, Goldstein LB. Guidelines for the early management of patients with ischemic stroke. American Heart Association Journals, 2005; 36:91-923.

3. Misbach J. Stroke: Aspek Diagnostik, Patofisiologi, Manajemen. Badan Penerbit FKUI, Jakarta, 2011.

4. Kementerian Kesehatan RI. Keputusan Menteri Kesehatan RI nomor 1457/MENKES/SK/X/2003 tentang Standar Pelayanan Minimal Bidang Kesehatan di Kabupaten/Kota

5. Kementerian Dalam Negeri. Peraturan Menteri Dalam Negeri Nomor 19 tahun 2011 tentang pedoman pengintegrasian layanan sosial dasar di pos pelayanan terpadu.

6. Sudarman. Penerapan metode collaborative learning untuk meningkatkan pemahaman materi mata kuliah metodologi penulisan. Jurnal pendidikan inovatif, 2008; 3(2): $94-100$.

7. Jones KA, Jones JL. Making cooperative learning worked in the college classroom: an application of 'five pillars' of cooperative learning to post-secondary instruction. The journal of effective teaching, 2008; $8(2): 61-76$. 
8. Harsono. Student Centered Learning di perguruan tinggi. Jurnal pendidikan kedokteran dan profesi kesehatan Indonesia, 2008; 3(1): 4 - 8.

9. Jauch EC, Saver JL, Adams HP, Bruno A. Guidelines for the early management of patients with acute ischemic stroke: a guideline for heatlhcare professionals from the American Heart Association/ America Stroke Association. Stroke-AHA Journals, January 2013.

10. Kusumawati Y, Darnoto S. Pelatihan peningkatan kemampuan kader posyandu dalam penanggulangan demam berdarah Dengue (DBD) di Kelurahan Joyotakan Kecamatan Serengan Surakarta. Warta, September 2008; 11(2): 159 - 169.
11. Jamil R. Training Need Analysis (TNA) practices: a survey of the top 1000 companies in Malaysia. VOT No: 75171, 2006.

12. Syafei M, Lazuardi L, Hasanbasri M. Pemberdayaan kader dalam revitalisasi posyandu di Kabupaten Batanghari. Jurnal KMPK, Working paper series, No. 14, April 2008, first draft.

13. Faust JL, Paulson DR. Active learning in the college classroom. Journal on excellence in college teaching, 2008; 9 (2): 3 - 24.

14. Jacobs G. Cooperative Learning: theory, principles, and techniques. JF New Paradigm Education, 2004.

15. Macpherson A. Cooperative learning group activities for college courses: a guide for instructor. Kwantlen University College, 2007. 